Article

\title{
Application of $X$-rays Diffraction for Identifying Thin Oxide Surface Layers on Zinc Coatings
}

\author{
George Vourlias \\ Department of Physics, Aristotle University of Thessaloniki, 54124 Thessaloniki, Greece; gvourlia@auth.gr
}

Received: 15 July 2020; Accepted: 16 October 2020; Published: 20 October 2020

check for updates

\begin{abstract}
Structural characterization of compound material coatings is usually achieved using time-consuming and destructive techniques such as optical and electrical microscopy, which require the use of grinding processes not always compatible with the material. This paper reports on the effective use of a theoretical model based on $X$-ray diffraction to calculate the thickness and composition of thin oxide films formed on the surface of zinc coatings. Zinc coatings are widely used in industrial application as protective layers against the atmospheric corrosion of steel substrates. The thickness of single- and multi-layer coatings is estimated using grazing incidence $X$-ray diffraction and various incidence angles. The coatings were grown using hot-dip, pack cementation and thermal spray techniques, and their experimental characteristics were compared to the theoretically predicted values of thickness and composition. The results indicate the formation of a thin zinc oxide film on top of each coating, which acts as an isolation layer and protects the surface of the sample against the environmental corrosion. Finally, the penetration depth of the $X$-rays into the zinc-based coatings for grazing incidence and Bragg-Brentano $X$-ray diffraction geometries were calculated using theoretical equations and experimentally confirmed.
\end{abstract}

Keywords: XRD; coating; zinc oxide; hot-dip galvanizing; pack cementation; thermal spray

\section{Introduction}

Zinc coatings are technologically important for a wide range of protective applications including anticorrosion layers in wires, tanks and automotive manufacturing components depending on their chemical characteristics [1-12]. The thickness, structure and chemical composition is of particular interest for corrosion shield applications in the marine and architectural field. Atmospheric and marine corrosion processes significantly alter the properties of the coatings as the oxides formed on the surface are usually well adherent and passivate the surface. Thus, a thorough and detailed characterization of the coatings is required, which will allow the development of high quality, reliable and reproducible products. The information required to determine the structural properties of a coating are most commonly provided by optical or scanning electron microscopy characterization. However, these techniques do not allow the comprehensive evaluation of the coating, as information is provided only from a small area. Furthermore, microscopy characterization is a time-consuming method and is hardly applicable in limited size specimens, as cross-sectional cutting, polishing and in certain cases even chemical etching preparation is required $[13,14]$.

It is thus important to develop a faster, simpler and non-destructive characterization method that can provide a thorough analysis of thin films and coatings without affecting the material, such as the one proposed by Yamada to identify pharmaceutical coatings [15]. X-ray diffraction (XRD) is a high precision evaluation technique that provides important information regarding the structure characteristics of a coating while enabling chemical composition identification without causing any damage to the sample under investigation. Bragg-Brentano is a widely used XRD geometry (BB-XRD), which provides information about the compounds located on the surface of a sample as well as at a 
certain depth below the surface. The effectiveness of XRD depends on the penetration depth of the $X$-ray beam, which is related to the incidence angle. The penetration depth can be narrowed to the top surface layers using grazing incidence $X$-ray geometry (GI-XRD). Thus, controlling the incidence angle of the X-ray beam enables the overall identification of the composition of the coating as well as the precise stoichiometry of the surface layers [16,17].

This work presents the results of a detailed theoretical analysis of zinc coatings based on grazing incidence $X$-ray diffraction technique. The samples grown using the hot-dip galvanizing process $[1-4,8,13,14,16,18-20]$, chemical vapor deposition by pack cementation $[5-8,13,14,16,21-25]$ and wire flame thermal spray [9-14,16,26-28] were examined using scanning electron microscopy (SEM), Bragg-Brentano and grazing incidence XRD, with specific interest in the composition of the thin zinc oxide layer formed on the surface. The $X$-rays theoretical penetration depth for all three types of sample was also calculated and compared to the experimental results. The described methodology is the first approach of a non-destructive theoretical monitoring procedure of zinc coatings after deposition or after exposure to aggressive environments.

\section{Theoretical Calculations of the Penetration Depth of X-rays}

The functionality of $X$-ray diffraction analysis relies on the penetration depth of the $X$-ray beam, which depends strongly on the material properties, the wavelength and the incident angle of the $X$-ray beam. Here, we present theoretical calculations of the penetration depth for BB and GI-XRD geometry [29].

\subsection{Calculation of the Penetration Depth of $X$-rays in $B B-X R D$}

Bragg-Brentano $X$-ray diffraction has a unique geometric configuration where the angle of the $X$-ray incidence beam is equal to the angle between the diffracted beam and the surface of the sample. This enables accurate monitoring of the material parameters. An ideal sample of infinite thickness is considered here. The intensity of the $X$-ray incidence beam is $I_{0}$, while $\alpha$ is the incidence angle. The intensity of the beam diffracted by an essential part of the sample of thickness $\mathrm{d} x$ and width $\ell$, located at a distance $x$ below the surface, is given by the equation:

$$
\mathrm{I}=\kappa \mathrm{I}_{0} \mathrm{e}^{-\mu\left(x_{1}\right)} \mathrm{d} x
$$

where $k$ is the fraction of crystallites orientated so that they can diffract the incident beam, $\mu$ is the linear attenuation coefficient of the material, and $x_{1}$ is the length of the optic path of the incident beam in the material (Figure 1a). The intensity of the diffracted beam, which has passed through the optic path $x_{2}$ inside the material, is given by:

$$
\mathrm{I}_{\mathrm{D}}=\kappa \mathrm{I}_{0} \cdot \mathrm{e}^{-\mu\left(x_{2}\right)}
$$

Using Equations (1) and (2), the differentiation of the intensity can be written as:

$$
\mathrm{dI}_{\mathrm{D}}=\kappa \ell \mathrm{I}_{0} \cdot \mathrm{e}^{-\mu\left(x_{1}+x_{2}\right)} \mathrm{d} x
$$

Due to the geometric characteristics of BB-XRD geometry $\left(\ell=1 / \sin \alpha, x_{1}=x / \sin \alpha, x_{2}=x / \sin \beta\right.$, $\alpha=\beta=\theta, \beta$ is the diffraction angle), Equation (3) can take the form of:

$$
\mathrm{dI}_{\mathrm{D}}=\left(\kappa \mathrm{I}_{0} / \sin \theta\right) \mathrm{e}^{-2 \mu x / \sin \theta} \mathrm{d} x
$$

However, detection of the diffracted beam is possible only when the intensity $\mathrm{I}_{\mathrm{D}}$ is higher than the $\mathrm{I}_{\mathrm{D}}=0.001 \times \mathrm{I}_{0}$ limit, which corresponds to a penetration depth of $t_{\mathrm{BB}}$. The ratio $\mathrm{dI}_{\mathrm{D}}(x=0) / \mathrm{dI}_{\mathrm{D}}\left(x=t_{\mathrm{BB}}\right)$ $=\mathrm{e}^{2 \mu t \mathrm{BB} / \sin \theta}=1000$ can be calculated using Equation (4), which gives: 


$$
t_{\mathrm{BB}}=3.45 \cdot \sin \theta / \mu
$$

\subsection{Penetration Depth of X-rays in GI-XRD}

In GI-XRD geometry, the penetration depth of $X$-rays in a single compound material can be calculated using the equation [15,30-36]:

$$
t_{\mathrm{GI}}=\frac{-\ln (1-G)}{\mu\left[\frac{1}{\sin \Omega}+\frac{1}{\sin (2 \theta-\Omega)}\right]}
$$

where $G$ is the fraction of the incident beam absorbed by the material before the beam reaches the maximum penetration depth $t_{\mathrm{GI}}, \Omega$ is the incidence angle and $2 \theta-\Omega$ is the angle of the diffracted beam. As for BB-XRD geometry, the penetration depth depends strongly on the incidence angle. Equation (6) takes the form of Equation (5) when the BB-XRD geometry variables are used, resulting in $\alpha=\theta$ and $G=0.99$ (as the penetration depth is considered equal to the thickness at which the intensity of the incident beam is equal to $\left.\mathrm{I}_{\mathrm{D}} / 1000\right)$.

\subsection{Penetration Depth of X-rays in a Multilayered Material}

Even though Equation (6) provides essential knowledge about the characteristics of a single compound coating, it is not applicable to two-layered or multi-layered coatings. This section presents a theoretical calculation of the penetration depth of X-rays in a multi-layered coating, taking in consideration the fraction of the beam absorbed by each layer. First, a single layer coating of a linear attenuation coefficient $\mu_{\text {base }}$ is considered, named as base coating, tested by GI-XRD. Equation (3) now takes the form of (Figure 1b):

$$
\mathrm{dI}_{\text {Dbase }}=\kappa \mathrm{I}_{0} \mathrm{e}^{-\mu_{\text {base }} x\left(\frac{1}{\sin \Omega}+\frac{1}{\sin (2 \theta-\Omega)}\right)} \mathrm{d} x
$$

Integration over the examined area results in:

$$
\mathrm{I}_{\text {Dbase }}=\kappa \mathrm{I}_{0} \frac{-\left[\mathrm{e}^{\mu_{\text {base }} t_{\text {base }}\left(\frac{1}{\sin \Omega}+\frac{1}{\sin (2 \theta-\Omega)}\right)}-1\right]}{\mu_{\text {base }}\left(\frac{1}{\sin \Omega}+\frac{1}{\sin (2 \theta-\Omega)}\right)}
$$

where $t_{\text {base }}$ is the penetration depth of the beam in the base coating. Following, a second layer is placed on top of the base coating, named as layer one, of attenuation coefficient $\mu_{1}$ and thickness $d_{1}$. It is considered here that the $X$-ray beam passes through this new layer and reaches the underlying base coating. As a result, the intensity, $\mathrm{I}_{\text {Dcoated }}$, of the beam diffracted by both layers can be described by the equation (Figure 1c):

$$
\mathrm{dI}_{\text {Dcoated }}=\mathrm{I}_{0} \mathrm{e}^{-\mu_{1} \mathrm{~d}_{1}\left(\frac{1}{\sin \Omega}\right)}\left(\kappa \mathrm{K}^{-\mu_{\text {base }} x\left(\frac{1}{\sin \Omega}+\frac{1}{\sin (2 \theta-\Omega)}\right)} \mathrm{d} x\right) \mathrm{e}^{-\mu_{1} \mathrm{~d}_{1}\left(\frac{1}{\sin (2 \theta-\Omega)}\right)}
$$

If the total penetration depth inside the base coating is $t_{b a s e, 1}$ then integration of Equation (9) results in: 


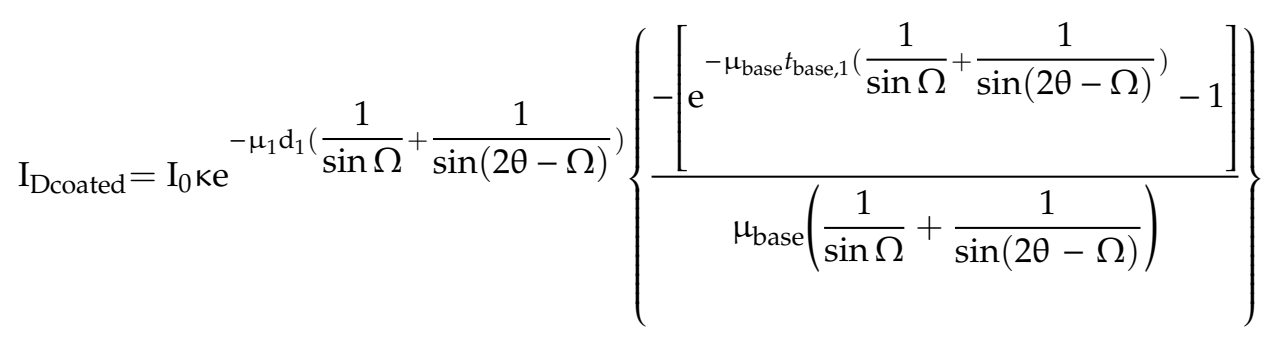

The ratio $\mathrm{I}_{\text {Dcoated }} / \mathrm{I}_{\text {Dbase }}$ is equal to:

$$
\frac{\mathrm{I}_{\text {Dcoated }}}{\mathrm{I}_{\text {Dbase }}}=\frac{\mathrm{e}^{-\mu_{1} \mathrm{~d}_{1}\left(\frac{1}{\sin \Omega}+\frac{1}{\sin (2 \theta-\Omega)}\right)\left[\mathrm{e}^{-\mu_{\text {base }} t_{\text {base }, 1}\left(\frac{1}{\sin \Omega}+\frac{1}{\sin (2 \theta-\Omega)}\right)}-1\right]}}{\mathrm{e}^{-\mu_{\text {base }} t_{\text {base }}\left(\frac{1}{\sin \Omega}+\frac{1}{\sin (2 \theta-\Omega)}\right)}-1}
$$

where $\mu_{\text {base }} t_{\text {base }}=\mu_{1} d_{1}+\mu_{\text {base }} t_{\text {base }, 1}$.

If the thickness $d_{1}$ of the epilayer, the linear attenuations $\mu_{1}$ and $\mu_{\text {base }}$ and the incidence angle $\Omega$ are known, then the thickness $t_{\text {base }, 1}$ of the penetration depth inside the base coating (after passing through layer one) is given by equation:

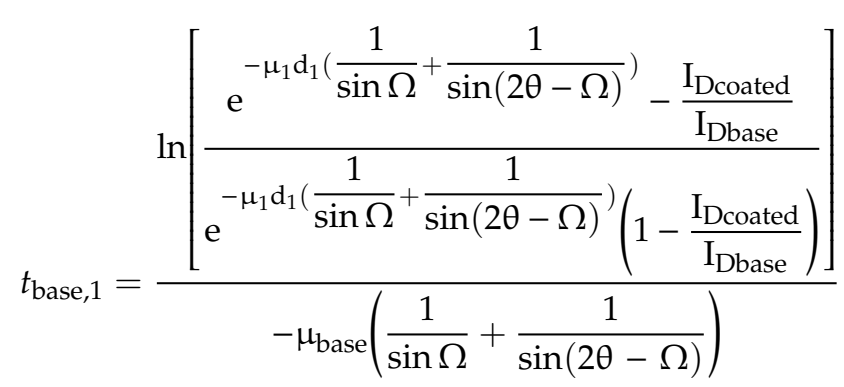

The above-described process can also be used for multilayered coatings. For example, for a three-layered coating (base layer, layer one and layer two), the penetration depth of the X-rays in the base layer, after passing through the two epilayers, will be given by:

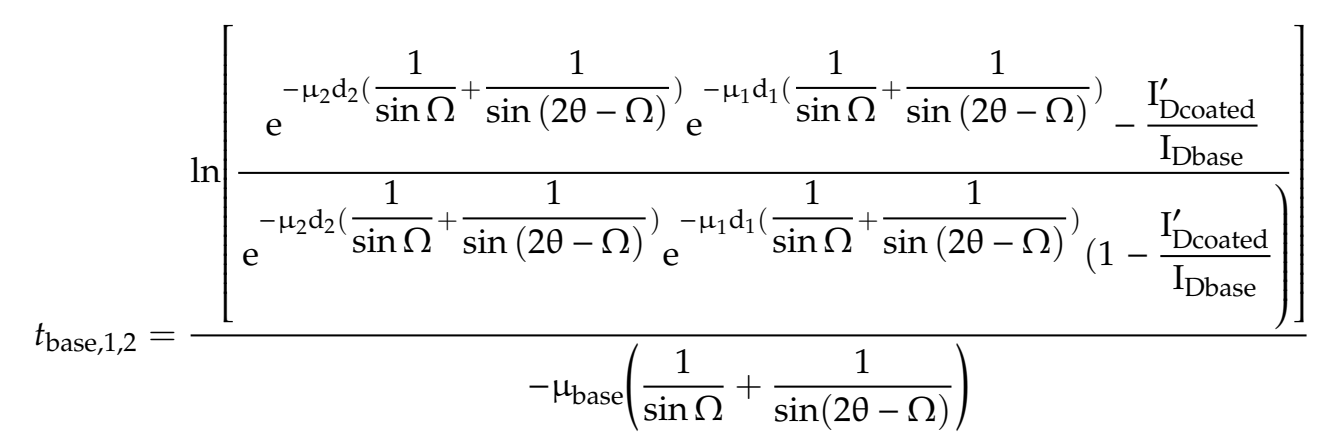

where $\mu_{2}$ and $d_{2}$ are the linear coefficient and thickness of the new layer (layer 2), respectively, and $\mathrm{I}_{\text {Dcoated }}^{\prime}$ is the total diffracted beam by the three-layered coating. 

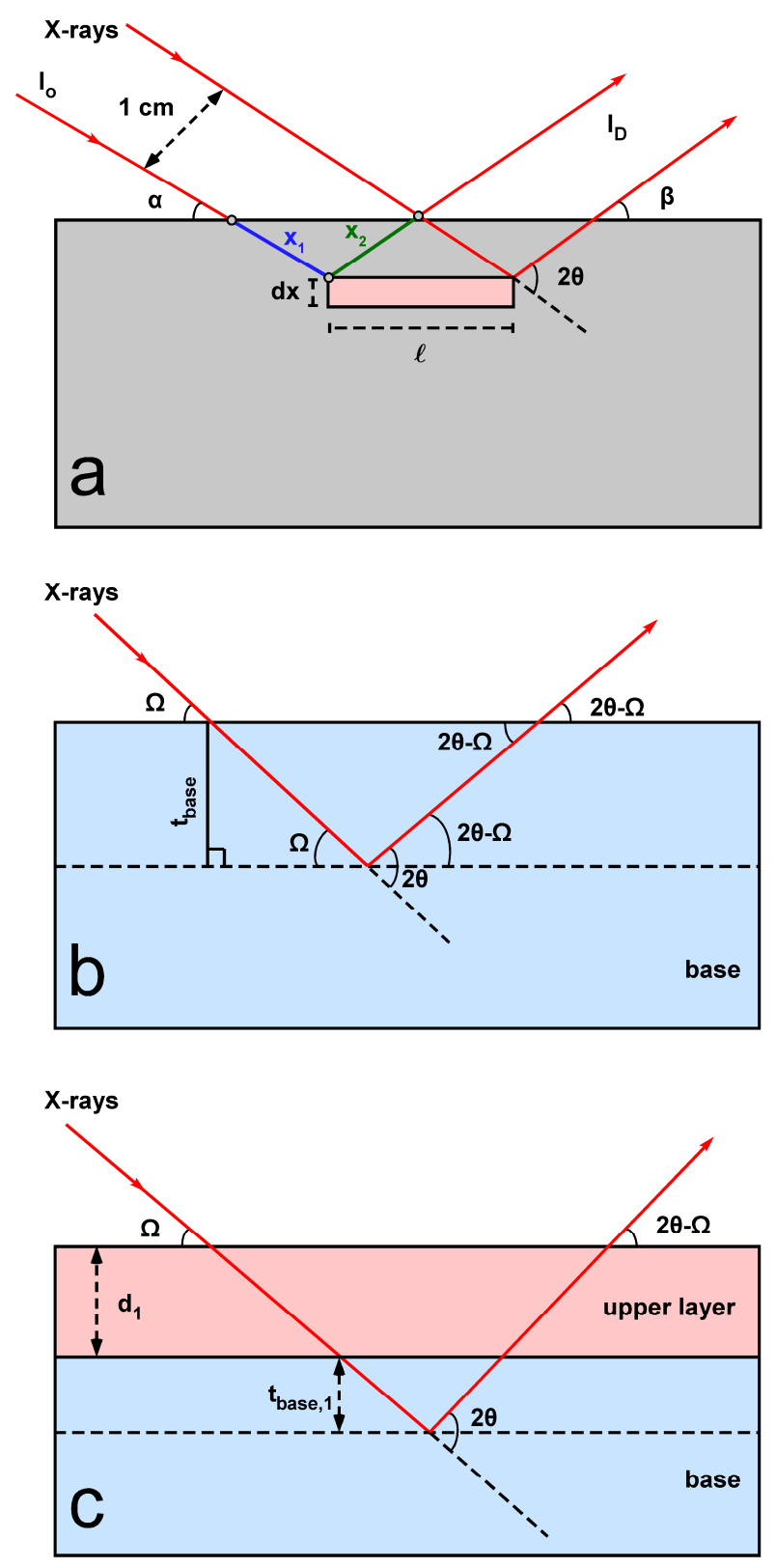

Figure 1. Schematic representation of X-ray diffraction in a flat sample. (a) Schematic representations of $X$-ray diffraction in a flat sample from the second layer of the examined material (b) and from both formed layers (c).

\subsection{Evaluation of the Penetration Depth of X-rays in Particular Zn Compounds}

According to previous publications [1,2,11,18], Zn-Fe and Zn compounds are the most favorable to be formed during the growth of zinc coatings. The penetration depth of $X$-rays in several $\mathrm{Zn}-\mathrm{Fe}$ compound coatings was calculated using Equation (5). The calculations were based on the diffraction angles of the first three, stronger peaks of the $X$-ray diffraction pattern of each $\mathrm{Zn}$ phase (presented by decreasing intensity). Table 1 shows the linear attenuation coefficients of these phases and the penetration depth in each case [36,37]. 
Table 1. The linear attenuation coefficients of $\mathrm{Zn}, \mathrm{ZnO}$ and $\mathrm{Zn}-\mathrm{Fe}$ compounds and the penetration depth of X-rays in BB-XRD calculated using Equation (5).

\begin{tabular}{cccc}
\hline Phase & $\boldsymbol{\mu}\left(\mathbf{c m}^{-\mathbf{1}}\right)$ & $\left.\boldsymbol{\theta} \mathbf{(}^{\mathbf{}}\right)$ & $\boldsymbol{t}(\boldsymbol{\mu m})$ \\
\hline \multirow{2}{*}{-phase } & \multirow{2}{*}{430.300} & 21.616 & 29.540 \\
$(\mathrm{Zn})$ & & 18.148 & 24.970 \\
& & 41.051 & 52.650 \\
\hline \multirow{2}{*}{-phase } & \multirow{2}{*}{549.890} & 20.749 & 22.227 \\
FeZn $_{13}$ & & 21.294 & 22.784 \\
& & 44.394 & 43.918 \\
\hline \multirow{2}{*}{$\delta$-phase } & \multirow{2}{*}{576.350} & 21.138 & 21.586 \\
FeZn $_{10}$ & & 20.544 & 21.006 \\
& & 20.892 & 21.346 \\
\hline \multirow{2}{*}{$\Gamma$-phase } & \multirow{2}{*}{749.701} & 21.338 & 15.796 \\
$\mathrm{Fe}_{3} \mathrm{Zn}$ & 21.800 & 16.122 \\
& & 20.709 & 15.351 \\
\hline \multirow{2}{*}{$\mathrm{ZnO}$} & \multirow{2}{*}{287.973} & 18.128 & 37.276 \\
& & 15.886 & 32.793 \\
& & 17.210 & 35.447 \\
\hline
\end{tabular}

The penetration depth for GI-XRD geometry was also calculated for these phases, using again the diffraction angles corresponding to the highest intensity peaks of the diffraction pattern and Equation (6). Figure 2 shows the dependence of the penetration depth to the incidence angle for each Zn phase.

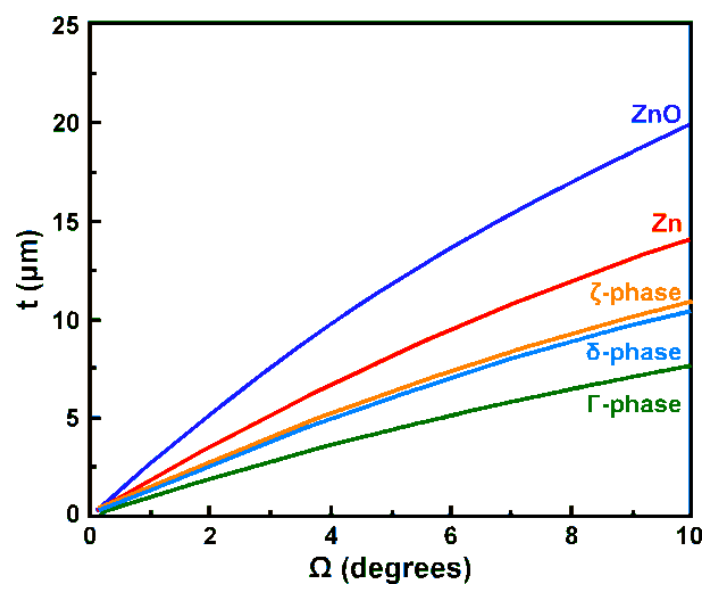

Figure 2. The dependence of the penetration depth of X-rays in $\mathrm{Zn}, \mathrm{ZnO}$ and in $\mathrm{Zn}-\mathrm{Fe}$ phases to the incidence angle for the grazing incidence $X$-ray geometry (GI-XRD). The angle corresponds to the diffraction peaks with the highest intensity.

\section{Experimental Details}

\subsection{Growth Processes}

Zinc coatings were grown on a commercial hot rolled low carbon steel sheet St-37 (information regarding the chemical composition are provided by the standard alloy numbering system of the Society of Automotive Engineers (SAE) SAE 1010, Table 2) using three different growth techniques, namely hot-dip galvanizing, chemical vapour deposition by pack cementation and wire flame thermal spraying, to verify the results presented in the previous section. Details on the type of substrate have been reported previously $[8,22]$. These coatings form a protective layer on the surface with a sacrificial and barrier effect, which prevents diffusion of the corrosive elements [38-41]. 
Table 2. Chemical composition (wt.\%) of SAE 1010 specimens.

\begin{tabular}{ccccccc}
\hline Fe & $\mathbf{C}$ & Mn & S & P & Si & Al \\
\hline Balance & 0.11 & 0.55 & 0.012 & 0.016 & 0 & 0 \\
\hline
\end{tabular}

During hot-dip galvanizing, the substrates were immersed in a graphite crucible with molten zinc, inside an electric furnace. The dipping temperature was $450{ }^{\circ} \mathrm{C}$ and the total time $3 \mathrm{~min}$. Prior to galvanizing, the coupons were degreased in $\mathrm{H}_{3} \mathrm{PO}_{4}$ solution, pickled and deoxidized in an $16 \% \mathrm{HCl}$ aqueous solution and finally fluxed in a $50 \% \mathrm{ZnCl}_{2}-2 \mathrm{NH}_{4} \mathrm{Cl}$ aqueous solution [1,2,41,42]. As a result, the immersed substrates were covered by a zinc layer alongside some internal $\mathrm{Fe}-\mathrm{Zn}$ phase layers. Prior to the pack cementation deposition, the substrates were packed and sealed in porcelain crucibles together with a powder mixture containing $3 \% \mathrm{NH}_{4} \mathrm{Cl}$ (activator), $50 \% \mathrm{Zn}$ (donor material) and $\mathrm{Al}_{2} \mathrm{O}_{3}$ (filler) as balance. The crucibles were then inserted in an Ar purged electric furnace at $400^{\circ} \mathrm{C}$ for $60 \mathrm{~min}$. As a result, the formed coating had a similar thickness to the galvanized coating but different chemical composition-Consisting only of Fe-Zn phases $[16,41,43]$. Finally, for the wire flame thermal spraying, the substrates were previously degreased with a $10 \% \mathrm{HCl}$ solution and then sandblasted in order to create the necessary roughness for coating adhesion. The deposition process was performed using a METCO 14E wire flame spray gun, keeping $120 \mathrm{~mm}$ spraying distance. The donor material was $99.9 \%$ pure $\mathrm{Zn}$ in form of a $2.4 \mathrm{~mm}$ diameter wire. The molten particles, produced from the wire melting by the combustion flame, were accelerated by compressed air towards the substrate, forming a characteristic rough laminar thick coating consisting of $\mathrm{Zn}$ and $\mathrm{ZnO}$. The average thickness of the coating was much higher (over $200 \mu \mathrm{m}$ ) in comparison to the other techniques [41,44].

\subsection{Characterization of Coatings}

Characterization of the structure, morphology and chemical composition of the coatings was performed using a $20 \mathrm{kV}$ JEOL 840A scanning electron microscope (SEM, Jeol Ltd., Akishima, Tokyo, Japan). The SEM was equipped with an OXFORD INCA Energy Dispersive X-ray Spectroscopy (EDS) analyzer (Oxford Instruments Nanoanalysis, Oxford, UK) and the INCA 18D 4.15 software that enabled point microanalysis and linear microanalysis of the area of interest. In order to perform the cross-section examination, the samples were cut with low speed saw, polished down to $5 \mu \mathrm{m}$ using alumina emulsion and then suitably etched with Nital solution. X-ray diffraction was carried out for the $\mathrm{Zn}$ phase identification, using a 2-circles Regaku Ultima+ diffractometer ( $\mathrm{CuK} \alpha$ radiation, 40 KV, 30 mA) with Bragg-Brentano (BB-XRD, Rigaku Corporation, Shibuya-Ku, Tokyo, Japan) and grazing incidence geometry (GI-XRD, Rigaku Corporation, Shibuya-Ku, Tokyo, Japan), using $1.5^{\circ}$ and $5^{\circ}$ incidence angle $(\Omega)$. This angle range is identified as suitable to get sufficient information of the composition of the top surface layers.

\section{Results and Discussion}

\subsection{Hot-Dip Galvanized Coatings}

BB-XRD diffraction characterization of the hot-dip galvanized zinc coating confirmed the formation of several Zn compounds (Figure 3a,b). Diffraction peaks and Zn phases identification was accomplished using the following powder diffraction file (PDF) cards: 04-0831 (Zn), 65-3411 (ZnO), 45-1184 (delta phase), 65-1238 (zeta phase) [45]. Namely, various Zn phases were confirmed, such as phase eta, zeta and delta alongside the zinc oxide $(\mathrm{ZnO})$. According to theory, the strongest peak should be that of $\mathrm{Zn}$, which corresponds to the (101) reflection. However, the strongest intensity peak in the diffraction pattern of Figure 3 corresponds to (102) Zn peak, indicating a preferable growth orientation for the $\mathrm{Zn}$ crystals. This is attributed to the cooling rate following the immersion of the samples in the $\mathrm{Zn}$ liquid bath and the presence of $\mathrm{Fe}-\mathrm{Zn}$ grains in the eta phase of the coating. These grains act as nucleation sites that favor the (102) growth direction instead of the (101). 

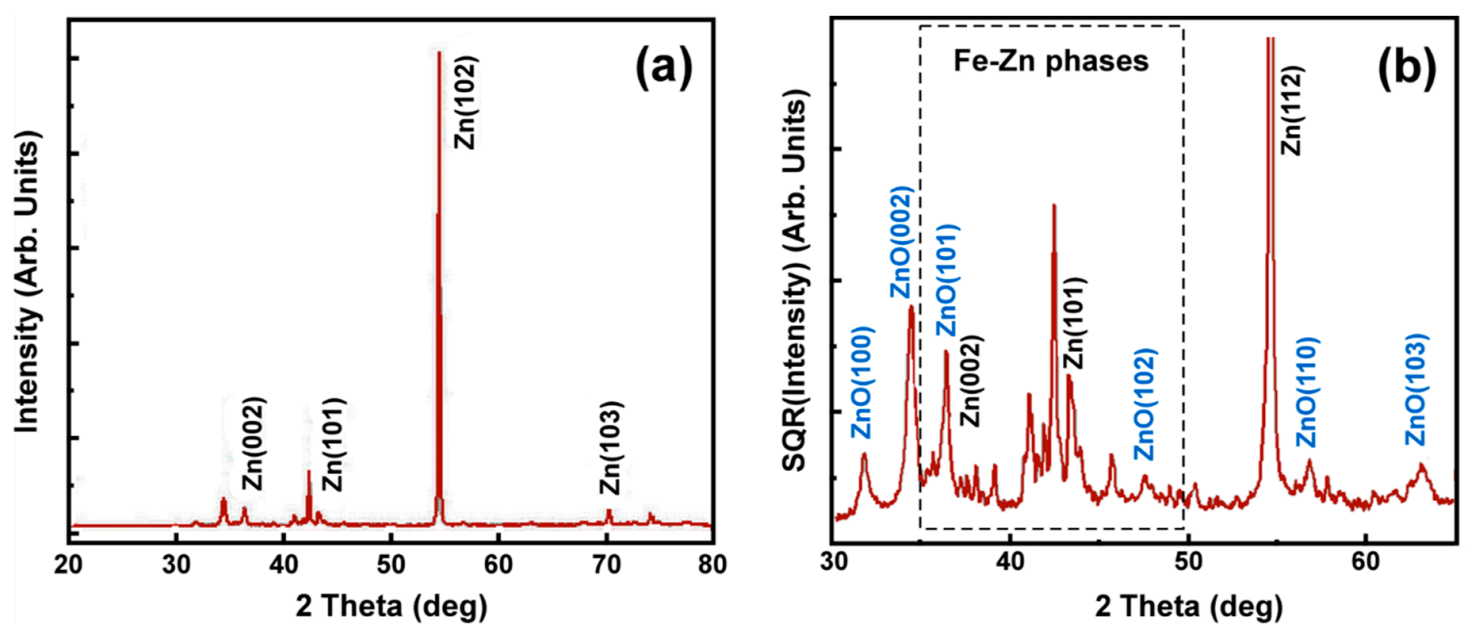

Figure 3. Bragg-Brentano (BB-XRD) diffraction pattern of the hot-dip galvanized sample with intensity on the (a) and the square root of the intensity (b) on the $y$-axis, respectively. Use of the square root enables identification of even the lowest intensity peaks of the XRD pattern.

SEM micrograph analysis was also used to confirm the various $\mathrm{Zn}$ phases present in the coating. As shown in the SEM micrograph of Figure 4a, the presence of eta, zeta and delta $\mathrm{Zn}$ phases were formed in layers. EDS analysis indicated a Fe concentration of 7-11.5 wt. $\%$ and $5-6 \mathrm{wt} . \%$ in the delta and zeta phase, respectively. The oxygen concentration was lower than $4 \mathrm{wt} . \%$. The top layer has an average thickness of $18 \mu \mathrm{m}$ and consisted entirely of eta phase. As shown in Table 1, for an X-ray incidence angle higher than $18,146^{\circ}\left(2 \theta>36^{\circ}\right)$, the penetration depth in eta phase is larger than $25 \mu \mathrm{m}$. This is significantly higher compared to the thickness of the eta phase layer thus the X-ray beam fully penetrates this phase and reaches the underlying zeta phase layer.
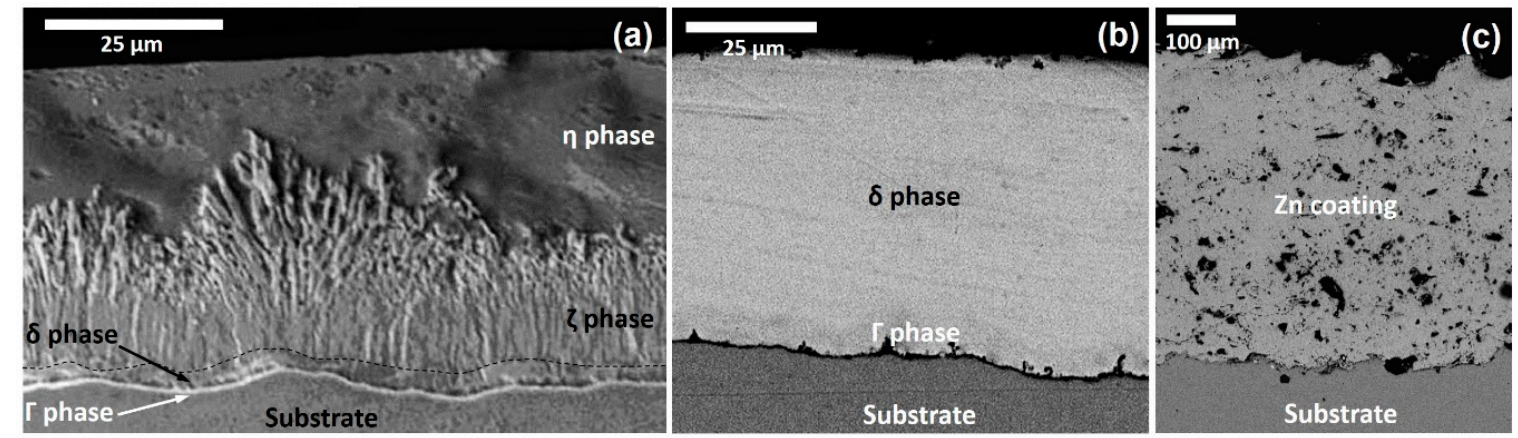

Figure 4. SEM micrograph of the cross section of the coatings deposited by hot-dip galvanizing (a), pack cementation (b) and thermal spray (c).

In addition, examination of the same samples with GI-XRD using an incidence angle of $5^{\circ}$ (Figure 5a) and $1.5^{\circ}$ (Figure 5b) confirmed the formation of eta phase and $\mathrm{ZnO}$ compounds in the top layer of the coating. Even though the penetration depth of the $X$-rays for an incidence angle of $5^{\circ}$ is low, the peaks of zeta and delta phases were not completely eliminated from the diffraction pattern (Figure 5a) due to precipitation of zeta phase crystallites in the mass of the eta-phase [2,42]. This is due to the detachment of zeta phase grains during their formation or formed during cooling right after the emersion of the samples from the $\mathrm{Zn}$ bath in areas saturated with iron. Moreover, in the same XRD pattern, the $\mathrm{ZnO}$ peaks have also significantly higher intensity as compared to that of the BB-XRD pattern (Figure 3). Their intensity is further increased in the GI-XRD pattern with incidence angle $1.5^{\circ}$ (Figure $5 \mathrm{~b}$ ). These results indicate that the $\mathrm{ZnO}$ oxides are restricted in the surface of the coating and can act as shield when the samples are exposed in aggressive environments. 

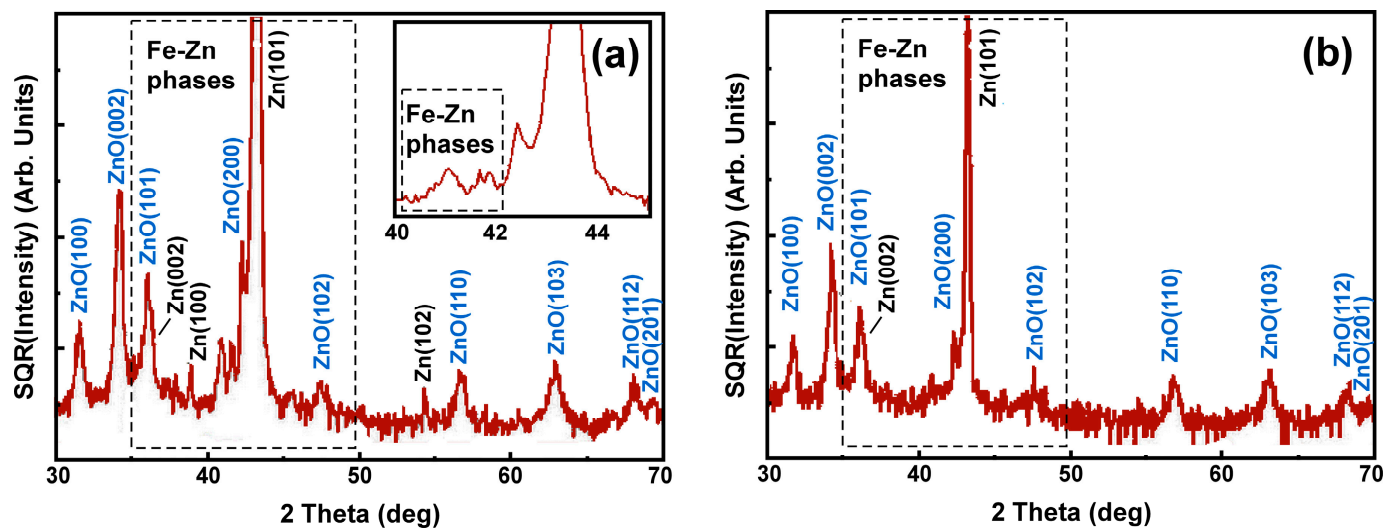

Figure 5. GI-XRD diffraction pattern of the hot-dip galvanized samples using an incidence angle of (a) $5^{\circ}$ and (b) $1.5^{\circ}$.

\subsection{Characterization of Pack Cementation Coatings}

BB-XRD examination of the samples grown by pack cementation revealed the existence of $\mathrm{ZnO}$ and Fe-Zn phases (Figure 6). Considering the SEM images shown in Figure 4b, two different FeZn phases can be identified. The EDS analysis indicated a Fe concentration of 8-12 wt.\% in the top thick layer and 20-25 wt.\% in the thin layer placed above the substrate confirming the formation of delta and gamma phase, respectively. The presence of gamma phase in the interface with substrate has been reported previously $[5,8,22]$. However, as the thickness of the delta phase layer is larger than the corresponding $X$-rays penetration depth, the gamma phase could not be identified in the $X$-rays diffraction pattern. In contrast to the XRD pattern of the galvanized samples, no Zn peak could be identified, while low intensity $\mathrm{ZnO}$ peaks are also present (concentration lower than $3 \mathrm{wt} . \%$ ). Furthermore, low intensity peaks corresponding to mixed Fe-Zn oxides were also present in the XRD pattern of Figure $6 \mathrm{~b}$. This is attributed to oxygen diffusion in the coating.
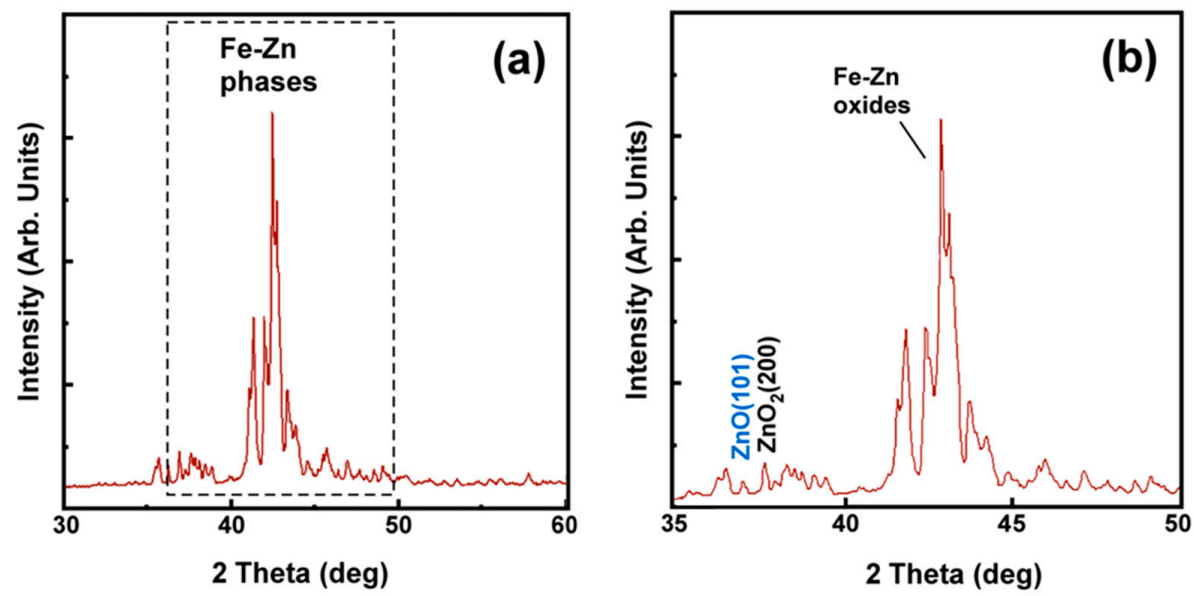

Figure 6. BB-XRD diffraction pattern (a) of the samples coated by pack cementation and (b) XRD pattern focusing on the framed area for the identification of the existing oxides. Peak identification was accomplished using the following PDF cards: 65-3411 and 65-0523 ( $\mathrm{ZnO}), 76-1364\left(\mathrm{ZnO}_{2}\right), 48-0567$ $\left(\mathrm{Fe}_{0.76} \mathrm{Zn}_{0.24} \mathrm{O}_{1.165}\right), 45-1184$ (delta phase) [45].

Furthermore, examination of the sample using small incidence angles GI-XRD (Figure 7a) confirmed the presence of the referred oxides into the first surface layers of the coatings. The corresponding oxides peaks in the GI pattern were much stronger as compared to those in the BB diagram, while the intensity of the delta phase peaks has been significantly decreased, especially in the $1.5^{\circ}$ incidence angle pattern (Figure $7 \mathrm{~b}$ ). In this case, the crystals did not demonstrate any 
preferable growth orientation as following deposition process the samples were left to cool down slowly in the furnace using a slow cooling rate. These conditions do not favour the crystallization along specific crystalline orientations.
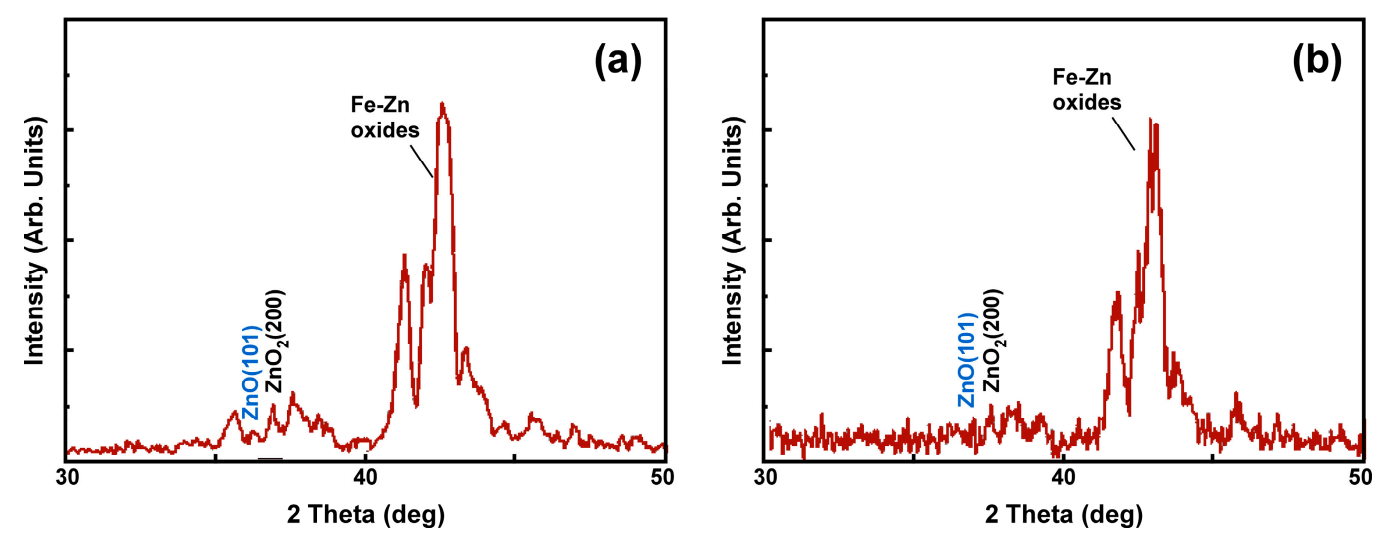

Figure 7. GI-XRD diffraction pattern of the samples grown using pack cementation with an incidence angle of (a) $5^{\circ}$ and (b) $1.5^{\circ}$, respectively.

\subsection{Characterization of Thermal Sprayed Zn Coatings}

Figure 8a shows the BB-XRD pattern of the thermal sprayed Zn coating, indicating the presence of pure zinc. This is due to the fact that during thermal spray deposition, the diffusion processes are eliminated leading to confinement of the formation of $\mathrm{Fe}-\mathrm{Zn}$ phases. This was also confirmed by the SEM image shown in Figure 4c. The GI-XRD diffractograms for both $5^{\circ}$ and $1.5^{\circ}$ were similar (Figure 8b,c). This is attributed to the characteristic rough surface morphology of such coatings $[13,14,16]$. It also important to mention that as the $\mathrm{Zn}$ diffraction peaks are very strong, low intensity peaks arising from very small concentrations of $\mathrm{Zn}$ compounds could not be identified in the pattern. To decrease the surface roughness, which is mainly responsible for the hide out of low intensity peaks, the thermal sprayed samples were mechanically polished. As a result, low intensity $\mathrm{ZnO}$ peaks were observed in the BB-XRD diffraction pattern of the polished samples (Figure 9). As reported previously [44], the oxidation of liquid metal droplets as they "flight" from the pistol flame to the substrate during deposition leads to the formation of $\mathrm{ZnO}$ oxides. Moreover, additional oxides were formed after the polishing process required to decrease the noise in the $\mathrm{X}$-ray patterns as the $\mathrm{Zn}$ is very reactive and can oxidized immediately.
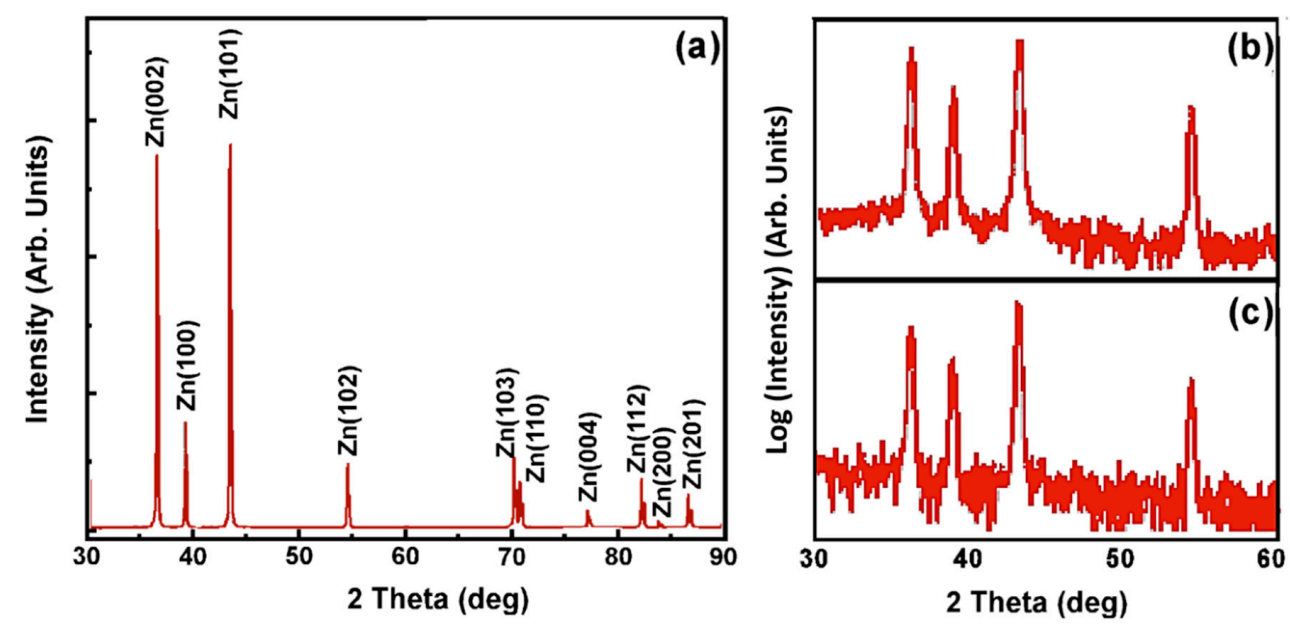

Figure 8. (a) BB-XRD diffraction pattern of the samples grown by thermal spray. GI-XRD diffraction patterns of the same samples obtained using an incidence angle of (b) $5^{\circ}$ and (c) $1.5^{\circ}$. 


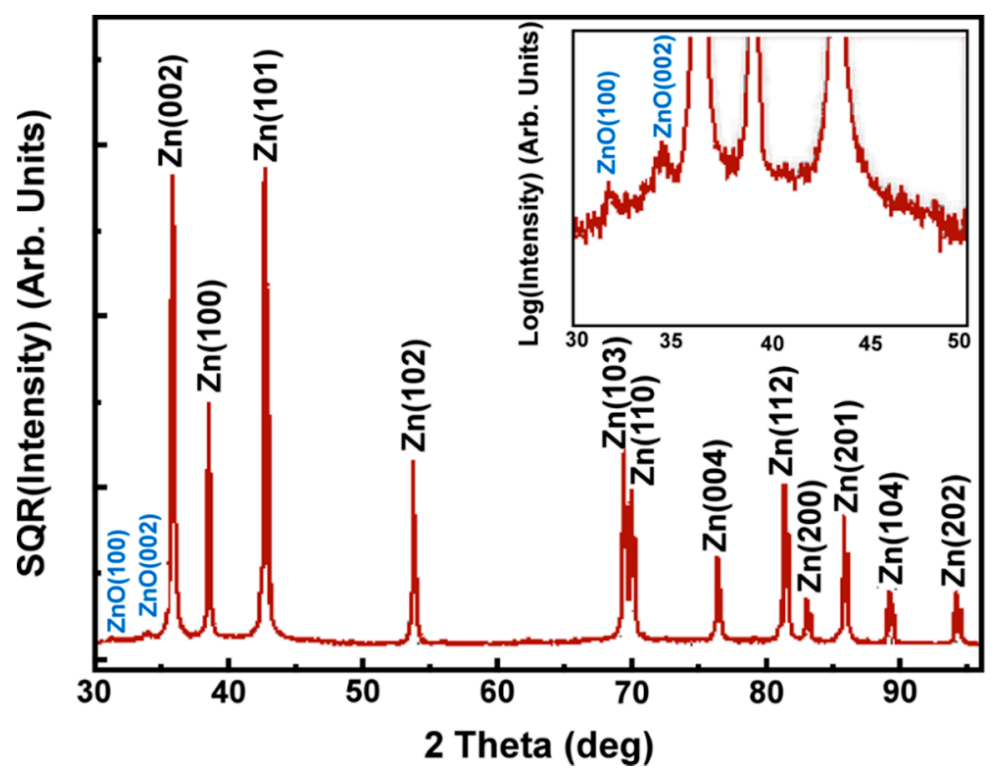

Figure 9. BB-XRD diffraction pattern of the polished samples grown by thermal spray. The inset pattern is a zoom-in to the area of interest ( $\mathrm{ZnO}$ peaks).

\subsection{Experimental Verification of the Theoretical Calculations}

In this section, Equation (12) is experimentally verified using a hot-dip galvanized sample that was exposed to $350^{\circ} \mathrm{C}$ in inert atmospheric for $6 \mathrm{~h}$. Two layers were formed due to the oxidation process, one of pure $\mathrm{Zn}$ material and one of $\mathrm{Zn}$ oxides $(\mathrm{ZnO})$ on top. This procedure was followed in order to deal with a pure $\mathrm{ZnO}$ and $\mathrm{Zn}$ phases and not with complicated $\mathrm{Zn}-\mathrm{Fe}$ phases, as following oxidation these phases are not easily reachable by the $X$-ray beam. We can assume that the top layer (scale) formed on the sample consists of $\mathrm{ZnO}$ as this phase is thermodynamically favored. The average thickness of this layer was evaluated using SEM to $f=10 \pm 2 \mu \mathrm{m}$ (Figure 10b). In case of GI-XRD examination ( $\Omega=5 \mathrm{deg}$ ) of this sample, the beam is expected to pass through the $\mathrm{ZnO}$ layer and reach the $\mathrm{Zn}$ layer, as according to Figure 2 the theoretically calculated penetration depth into $\mathrm{ZnO}$ is bigger than $10 \mu \mathrm{m}$. To get the penetration depth of the beam into the underling $Z n$ layer, the integrated area of the main $\mathrm{Zn}$ GI-XRD diffracted peaks $\left(2 \theta=43.23^{\circ}\right)$ of the non-oxidized $\mathrm{Zn}$ sample (Figure $5 \mathrm{a}$ ) and the hot-dip oxidized sample (Figure 10) was obtained in order to calculate the ratio $\mathrm{I}_{\text {Dcoated }} / \mathrm{I}_{\text {Dbase }}=\mathrm{I}_{\text {Dcoated }} / \mathrm{I}_{\mathrm{DZn}}$, as the linear attenuation coefficients of $\mathrm{Zn}$ and $\mathrm{ZnO}$ are already known. Using Equation (12), it was concluded that the penetration depth into the underlying layer is $t_{\mathrm{base}, 1}=t_{\mathrm{Zn}}=1.257 \mu \mathrm{m}$. As a result, the penetration depth into the oxidized sample is $d=f+t_{\mathrm{Zn}}=11.257 \mu \mathrm{m}$. The empirical law of Beer-Lambert for a $\mathrm{Zn}$ and a $\mathrm{ZnO}$ layer was also used to calculate the experimental $X$-ray's penetration depth resulting in $\mathrm{I}_{Z n}=\mathrm{I}_{0} \mathrm{e}^{\mu \mathrm{Zn}{ }^{*} t \mathrm{Zn}}$ and $\mathrm{I}_{\mathrm{ZnO}}=\mathrm{I}_{0} \mathrm{e}^{\mu \mathrm{ZnO} \mathrm{O}^{*} \mathrm{ZnO}}$. For thicknesses such that $\mathrm{I}_{\mathrm{Zn}}=\mathrm{I}_{\mathrm{ZnO}}$, the empirical low leads to $t_{\mathrm{ZnO}}=t_{\mathrm{Zn}} \cdot \mu_{\mathrm{Zn}} / \mu_{\mathrm{ZnO}}$. If the sample was completely consisted of $\mathrm{ZnO}$, instead of $\mathrm{Zn}$ and $\mathrm{ZnO}$, then $t_{\mathrm{Zn}}$ could be replaced by $t_{\mathrm{ZnO}}$, and $d=f+t_{\mathrm{Zn}} \cdot \mu_{\mathrm{Zn}} / \mu_{\mathrm{ZnO}}=11.878 \mu \mathrm{m}$, which is in good agreement with the $\mathrm{ZnO}$ penetration depth shown in Figure 2 for an incident angle of $5^{\circ}$.

This result alongside the SEM thickness measurement indicates that the initial calculations obtained using Equation (12) were correct and thus it could be used for the estimation of the penetration depth $(x)$ in a two layered material as follows: the thickness of the surface layer can be measured by varying the incident angle $\Omega$ of the $X$-rays at a certain range where the characteristic peaks of the underlying layer are barely visible. Under these conditions, the calculated penetration depth from Equation (6) corresponds to the thickness of the surface layer. 


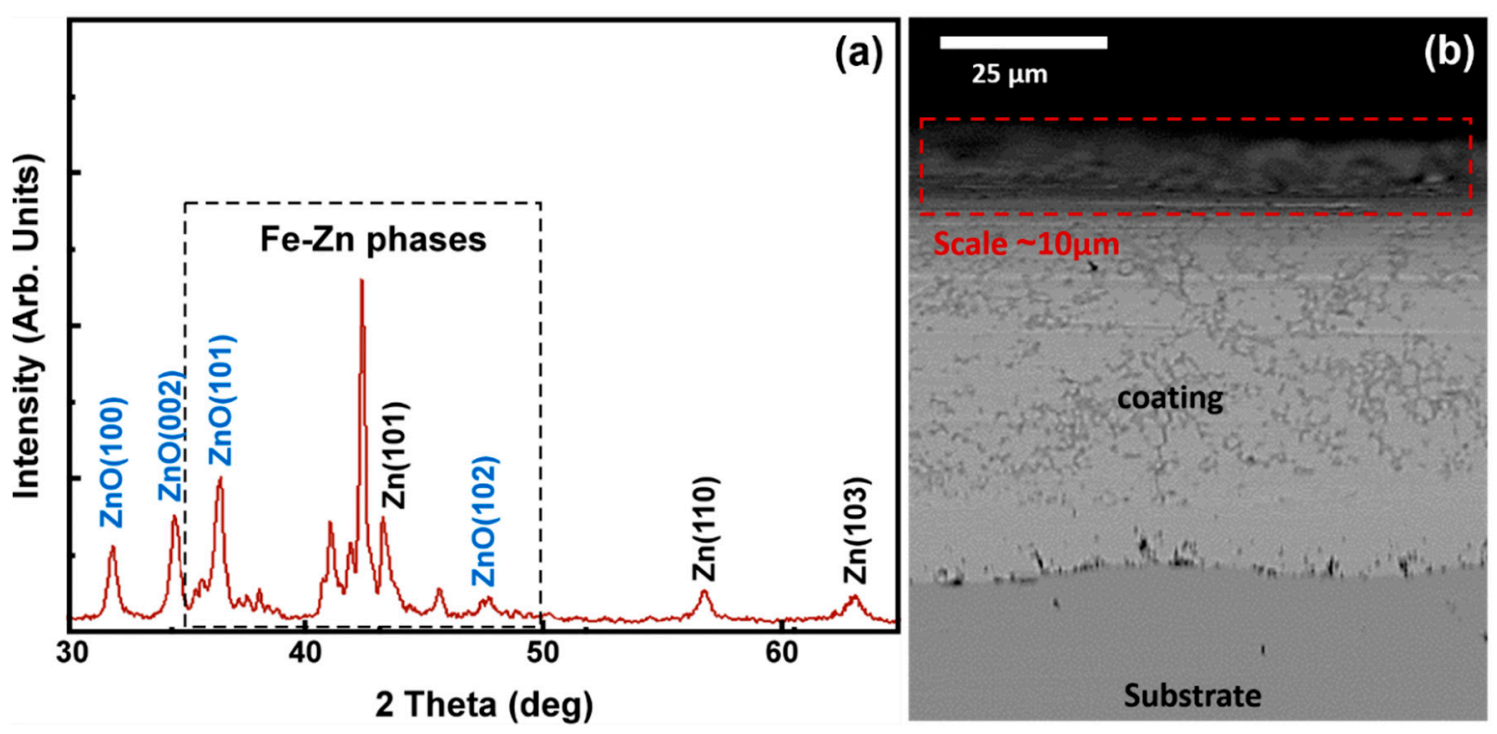

Figure 10. (a) GI-XRD pattern and (b) SEM micrograph of the oxidized hot-dip coating.

\section{Conclusions}

XRD analysis was used to phase monitor zinc coatings deposited by the hot-dip galvanizing process, pack cementation and the thermal spray technique. Calculations of the penetration depth of $X$-rays in various $\mathrm{Zn}$ phases present in the coating were used to theoretically verify the experimental results. The final equation (Equation (12)), corresponding to the penetration depth of the $X$-rays in a two-layer coating, was verified by applying it to the $\mathrm{ZnO}$ layers formed on the surface of the hot-dip galvanized samples. The results obtained using traditional methods such as SEM and XRD analysis were found to be in excellent agreement with those calculated by Equation (12). It was concluded that regardless of the structure and chemical content of the $\mathrm{Zn}$ coatings, a varied thickness thin zinc oxide film is formed on top of the as-deposited coatings. This oxide film is expected to offer additional protection to the metallic components/steel against aggressive environmental factors.

Funding: This research received no external funding.

Acknowledgments: I gratefully acknowledge K. Papanastasiou, D.D. Chaliampalias, N. Pistofidis, and E. Delli for their substantial assistance in the experimental procedure and data processing.

Conflicts of Interest: The authors declare no conflict of interest.

\section{References}

1. Marder, A.R. The metallurgy of zinc-coated steel. Prog. Mater. Sci. 2000, 45, 191-271. [CrossRef]

2. Vourlias, G.; Pistofidis, N.; Stergioudis, G.; Tsipas, D. The effect of alloying elements on the crystallization behavior and on the properties of galvanized coatings. Cryst. Res. Technol. 2004, 39, 23-29. [CrossRef]

3. Chen, X.; Li, C.; Bai, X.; Wang, H.; Xu, S.; Song, S. Microstructure, mechanical properties, abrasive wear, and corrosion behavior in molten zinc of boride-based coatings in situ synthesized by an HVOF spraying process. Coatings 2019, 9, 665. [CrossRef]

4. Thierry, D.; LeBozec, N.; Le Gac, A.; Persson, D. Long-term atmospheric corrosion rates of hot dip galvanised steel and zinc-aluminium-magnesium coated steel. Mater. Corros. 2019, 70, 2220-2227. [CrossRef]

5. Pistofidis, N.; Vourlias, G.; Chaliampalias, D.; Pavlidou, E.; Chrissafis, K.; Stergioudis, G.; Polychroniadis, E.K.; Tsipas, D. DSC study of the deposition reactions of zinc pack coatings up to $550{ }^{\circ} \mathrm{C}$. J. Therm. Anal. Calorim. 2006, 54, 191-194. [CrossRef]

6. Liu, Y.; Zhang, L.; Pei, L.; Sheng, H. Improved corrosion resistance of hydroxyapatite coating on carbon fiber by applying SiC interlayer. Appl. Surf. Sci. 2020, 512, 145692. [CrossRef] 
7. He, J.; Guo, X.; Qiao, Y. Oxidation behavior and adhesion performance of $\mathrm{TiSi}_{2}-\mathrm{NbSi}_{2}$ composite coating prepared via magnetron sputtering and then pack cementation. J. Alloys Compd. 2020, 820, 153425. [CrossRef]

8. Vourlias, G.; Pistofidis, N.; Chaliampalias, D.; Patsalas, P.; Stergioudis, G.; Tsipas, D. A comparative study of the structure and the corrosion behavior of zinc coatings deposited with various methods. Surf. Coat. Technol. 2006, 200, 6594-6600. [CrossRef]

9. Kawaguchi, Y.; Miyazaki, F.; Yamasaki, M.; Yamagata, Y.; Kobayashi, N.; Muraoka, K. Coating qualities deposited using three different thermal spray technologies in relation with temperatures and velocities of spray droplets. Coatings 2017, 7, 27. [CrossRef]

10. Curry, N.; VanEvery, K.; Snyder, T.; Markocsan, N. Thermal conductivity analysis and lifetime testing of suspension plasma-sprayed thermal barrier. Coatings 2014, 4, 630-650. [CrossRef]

11. Kahar, S.; Singh, A.; Vala, U.; Desai, A.; Smit Desai, S. Thermal sprayed coating using zinc: A review. Int. Res. J. Eng. Technol. 2020, 7, 6497-6503.

12. Milanti, A.; Koivuluoto, H.; Vuoristo, P.; Bolelli, G.; Bozza, F.; Lusvarghi, L. Microstructural characteristics and tribological behavior of HVOF-sprayed novel fe-based alloy coatings. Coatings 2014, 4, 98-120. [CrossRef]

13. Vourlias, G.; Pistofidis, N.; Chrissafis, K.; Stergioudis, G. Zinc coatings for oxidation protection of ferrous substrates: Part I. Macroscopic examination of the coating oxidation. J. Therm. Anal. Calorim. 2007, 90, 769-775. [CrossRef]

14. Vourlias, G.; Pistofidis, N.; Chrissafis, K.; Stergioudis, G. Zinc coatings for oxidation protection of ferrous substrates: Part II. Microscopic and oxidation mechanism examination. J. Therm. Anal. Calorim. 2007, 90, 777-782. [CrossRef]

15. Yamada, H.; Suryanarayanan, R. Calculation of the penetration depth of X-rays in intact pharmaceutical film-coated tablets by microdiffractometry. Pharm. Res. 2006, 23, 2149-2157. [CrossRef]

16. Chaliampalias, D.; Pistofidis, N.; Pavlidou, E.; Tsipas, D.; Stergioudis, G.; Vourlias, G. Resistance of different Zn coatings at elevated temperature air environments. Surf. Eng. 2016, 32, 53-60. [CrossRef]

17. Kolaklieva, I.; Kakanakov, R.; Chaliampalias, D.; Vourlias, G.; Cholakova, T.; Pashinski, C.; Chitanov, V.; Bahchedjiev, C.; Petkov, N.; Polychroniadis, E. Mechanical, structural and thermal properties of multilayered gradient nanocomposite coatings. J. Nano Res. 2012, 17, 193-202. [CrossRef]

18. Riyas, A.H.; Shibli, S.M.A. Assessment of the role of $\zeta$ - and $\delta$-phases in $\mathrm{ZrO}_{2}-\mathrm{Al}_{2} \mathrm{O}_{3}$ composite based hot dip zinc galvanized coating by layer wise tuning. Appl. Surf. Sci. 2019, 481, 972-986. [CrossRef]

19. Kania, H.; Saternus, M.; Kudláček, J.; Svoboda, J. Microstructure characterization and corrosion resistance of zinc coating obtained in a Zn-AlNiBi galvanizing bath. Coatings 2020, 10, 758. [CrossRef]

20. Yang, T.; He, Y.; Chen, Z.; Zheng, W.; Wang, H.; Li, L. Effect of dew point and alloy composition on reactive wetting of hot dip galvanized medium manganese lightweight steel. Coatings 2020, 10, 37. [CrossRef]

21. Choi, K.; Yang, W.; Baik, K.-H.; Kim, Y.; Lee, S.; Park, J.S. Growth kinetics and isothermal oxidation behavior of aluminide pack coatings on a multiphase Mo-Si-B alloy. Oxid. Met. 2019, 92, 423-437. [CrossRef]

22. Pistofidis, N.; Vourlias, G.; Chaliampalias, D.; Chrysafis, K.; Stergioudis, G.; Polychroniadis, E.K. On the mechanism of formation of zinc pack coatings. J. Alloys Compd. 2006, 407, 221-225. [CrossRef]

23. Chaia, N.; Cossu, C.M.F.A.; Ferreira, L.M.; Parrisch, C.J.; Cotton, J.D.; Coelho, G.C.; Nunes, C.A. Protective aluminide coating by pack cementation for Beta 21-S titanium alloy. Corros. Sci. 2019, 160, 108165. [CrossRef]

24. Chaia, N.; Cury, P.L.; Rodrigues, G.; Coelho, G.C.; Nunes, C.A. Aluminide and silicide diffusion coatings by pack cementation for Nb-Ti-Al alloy. Surf. Coat. Technol. 2020, 389, 125675. [CrossRef]

25. Chaliampalias, D.; Pistofidis, N.; Vourlias, G. Effect of temperature and zinc concentration on zinc coatings deposited with pack cementation. Surf. Eng. 2008, 24, 259-263. [CrossRef]

26. Guo, X.; Planche, M.-P.; Chen, J.; Liao, H. Relationships between in-flight particle characteristics and properties of HVOF sprayed WC-CoCr coatings. J. Mater. Process. Technol. 2014, 214, 456-461. [CrossRef]

27. Ce, N.; Paul, S. Thermally sprayed aluminum coatings for the protection of subsea risers and pipelines carrying hot fluids. Coatings 2016, 6, 58. [CrossRef]

28. Xie, M.; Lin, Y.; Ke, P.; Wang, S.; Zhang, S.; Zhen, Z.; Ge, L. Influence of process parameters on high velocity oxy-fuel sprayed $\mathrm{Cr}_{3} \mathrm{C}_{2}-25 \% \mathrm{NiCr}$. Coatings 2017, 7, 98. [CrossRef]

29. Papanastasiou, K. Study of Zinc Coatings in Correlation with the Penetration Depth of X-rays-Applications. Ref. No. GRI-2011-6023. Master's Thesis, Aristotle University of Thessaloniki, Thessaloniki, Greece, 7 July 2010. 
30. Angerer, P.; Mann, R.; Gavrilovic, A.; Nauera, G.E. In situ X-ray diffraction study of the electrochemical reaction on lead electrodes in sulphate electrolytes. Mater. Chem. Phys. 2009, 114, 983-989. [CrossRef]

31. Chaudhuri, J.; Shah, S. Thickness measurement of thin films by X-ray absorption. J. Appl. Phys. 1991, 69, 499-501. [CrossRef]

32. Huaqiang, W.; Bin, L.; Wei, M.; Xingtao, L.; Kun, T. Computed depth profile method of X-ray diffraction and its application to Ni/Pd films. Surf. Coat. Technol. 2002, 149, 198-205.

33. Doerner, M.F.; Brennan, S. Strain distribution in thin aluminum films using X-ray depth profiling. J. Appl. Phys. 1988, 63, 126-131. [CrossRef]

34. Eisenberger, P.; Marra, W.C. X-ray diffraction study of the Ge(001) reconstructed surface. Phys. Rev. Lett. 1981, 46, 1081-1084. [CrossRef]

35. Skrzypek, S.J.; Baczmanski, A.; Ratuszek, W.; Kusior, E. New approach to stress analysis based on grazing-incidence X-ray diffraction. J. Appl. Crystallogr. 2001, 34, 427-435. [CrossRef]

36. Hubbell, J.H.; McMaster, W.H.; Del Grande, N.K.; Mallett, J.H. X-ray crosssections and attenuation coefficients. In IUCr International Tables for X-ray Crystallography; Kynoch Press: Birmingham, UK, 1974; pp. 47-49.

37. Cullity, B.D.; Stock, S.R. Elements of X-ray Diffraction, 3rd ed.; Prentice Hall Inc.: New York, NY, USA, 2001; pp. 466-468.

38. Korb, L.J.; Olson, D.L. Hot Dip Coatings, Corrosion. In ASM Handbook; ASM International: New York, NY, USA, 1992; Volume 13, pp. 975-1009.

39. Korb, L.J.; Olson, D.L. CVD/PVD Coatings, Corrosion. In ASM Handbook; ASM International: New York, NY, USA, 1992; Volume 13, pp. 1035-1042.

40. Tucker, R.C. Thermal Spray Coatings in Surface Engineering. In ASM Handbook; ASM International: New York, NY, USA, 2000; Volume 5, pp. 1446-1471.

41. Pistofidis, N.; Vourlias, G.; Stergioudis, G.; Polychroniadis, E.K.; Tsipas, D. Corrosion Protection: Processes, Management and Technologies; Nova Publishing, Nova Science Publishers, Inc.: Hauppauge, NY, USA, 2009; Chapter 1, pp. 1-38.

42. Vourlias, G.; Pistofidis, N.; Stergioudis, G.; Pavlidou, E.; Tsipas, D. Influence of alloying elements on the structure and on the corrosion resistance of the galvanized coatings. Phys. Status Solidi (A) Appl. Res. 2004, 201, 1518-1527. [CrossRef]

43. Vourlias, G.; Pistofidis, N.; Chaliampalias, D.; Pavlidou, E.; Stergioudis, G.; Polychroniadis, E.K.; Tsipas, D. Zinc deposition with pack cementation on low carbon steel substrates. J. Alloys Compd. 2006, 416, 125-130. [CrossRef]

44. Chaliampalias, D.; Vourlias, G.; Pistofidis, N.; Stergioudis, G.; Polychroniadis, E.K. A morphological and microstructural study of flame-sprayed zinc coatings on low-alloyed steels as a contribution to explaining their corrosion resistance. Phys. Status Solidi (A) Appl. Res. 2008, 205, 1566-1571. [CrossRef]

45. Joint Committee on Powder Diffraction Standards (JCPDS). Powder Diffraction Files; International Centre for Diffraction Data (ICDD): Newton Square, PA, USA, 2003.

Publisher's Note: MDPI stays neutral with regard to jurisdictional claims in published maps and institutional affiliations.

(C) 2020 by the author. Licensee MDPI, Basel, Switzerland. This article is an open access article distributed under the terms and conditions of the Creative Commons Attribution (CC BY) license (http://creativecommons.org/licenses/by/4.0/). 